\title{
A statistical approach to the analysis of merger and acquisition efficiency in the Russian industry
}

\author{
M. Karelina ${ }^{1, *}$, and $V$. Mkhitarian ${ }^{2}$ \\ ${ }^{1}$ Nosov Magnitogorsk State Technical University, Magnitogorsk, Russia \\ ${ }^{2}$ National Research University Higher School of Economics, Moscow, Russia
}

\begin{abstract}
At present, the success of economic institution transformations, as well as creating an efficient economic system with a fundamental new nature of corporate relationships are impossible without the statistical recording of factors contributing to the efficiency of merger and acquisition transactions in the Russian industry. The paper proposes a method for analyzing the efficiency of merger and acquisition transactions of enterprises in the industrial sector of the Russian economy, based on simulation methods. The methodical approach developed to analyze the efficiency of the integration transactions of Russian industrial companies allows one to consider individual preferences of investors, as well as to give a complex statistical evaluation of the strategic economic benefits from M\&A transactions. This method enables to evaluate the probability and stability of the synergistic effect values within the increase of competitiveness of Russian industrial enterprises on the domestic and foreign markets.
\end{abstract}

\section{Introduction}

The current economic environment creates quite strict operating conditions for enterprises in the industrial sector in the economy of the Russian Federation. Only those companies can maintain and strengthen their competitive positions whose management is always concerned with the qualitative and quantitative growth; that develops effective business strategies for realization of which there may not be enough internal capacity. When internal reserves of increasing efficiency in activity have been exhausted, external development that is realized by means of mergers and acquisitions (M\&A) becomes an indispensable condition to ensure the continuity of the enterprise life cycle [1,2].

Issues of analysis of investment project efficiency with varying degrees of detail are considered in the works of Russian and foreign specialists. Vladimirova I.G., Gvardii S.V., Nikonova I.A., Rudyk N.B., Semenkova Ye.V., Chekun I.N, Breg C., Bishop D., Galpin T., Gokhan P., Depamfilis D, Koller T, Kouplend T, Lazhu A., Murrin Dzh., Porter M., Rid S., Khendon M., Evans F. analyzed the possible economic effects of mergers and acquisitions aimed to forecast their results and efficiency increasing.

Employees of such international consulting and auditing companies as Deloitte, Ernst and Young, KPMG, McKinsey, PricewaterhouseCoopers significantly contributed to the study of the merger and acquisition practice, to the investigation of their effects, the causes of failure and the development of methods and techniques for analysis of the expected results of the integration transactions.
Despite the presence of a large number of works devoted to the analysis of individual issues relating to merger and acquisition efficiency, a study of investigations in the field of M\&A showed that the greatest attention has been paid to the integration processes taking place in the banking sector. Transactions that are carried out in the industrial sector of the economy and have serious specificity remain insufficiently studied.

Mergers and acquisitions are a high-risk, expensive, and, at the same time, highly profitable kind of investment project whose potential can be realized only by transaction careful preparation, planning, analysis, and its efficiency justification [3]. All this causes the necessity for the development of a statistical approach to the analysis of merger and acquisition efficiency in the Russian industry.

\section{A systematic approach to the analysis of integration transaction efficiency of enterprises in the industrial sector in the economy of the russian federation}

In this work we determined the synergistic effect as a key parameter that affects the decision making process on integration within the framework of the justification of the merger and acquisition efficiency [4].

There are a number of approaches to the formation of an information base for analysis of the integration activity efficiency; for example, you can use the accumulated statistical information on the industrial enterprises, as well as promising data. For the solution of

Corresponding author: marjyshka@mail.ru 
this issue, we took into account the world practice of analysis of the integration project efficiency based on discounted cash flows generated by the companies participants of the integration [5].

When identifying the origin of the synergistic effect one should take into account only those opportunities that were not available for autonomous companies and resulted from mergers. Comparing and contrasting the plan of the strategic development of the merged company with the development plans of independent companies involved in M\&A transactions may help to solve this problem.

After the data on the supposed sources of the synergistic effect of mergers and acquisitions has been collected and the costs associated with their implementation have been described, you can proceed to the compilation of the forecasting bookkeeping balance sheet and profit and loss report. When forecasting the individual articles of these reports you should take into account the influence of auxiliary facilities that give rise to the synergistic effect [6].

At the same time, financial indicators, which are the basis of decision making on the expediency of the integration project are based on the point valuation for the most plausible data. This valuation is also point and does not provide complete information about the synergistic effect in the M\&A transaction. The transition from the point valuation to probability distributions of indefinite variables and the use of simulation technique allows you to get more exact information about the synergy as a foreseeable result of integration [7].

The need for simulation in studying the integration activity of industrial structures is caused by differences between the Russian market and the global total market. Simulation results supplemented by statistical estimation can provide the head of the integration project with more exact information about the extent of the impact of key factors on the expected results and possible scenarios.

The peculiarity of the use of the Monte Carlo method in the analysis of the synergistic effect in M\&A transactions is related to the ability to work with a model, as in case of conventional investment calculations and risk management of integration transactions derives from multiple calculation of the model. This method is most fully characterizes the whole range of uncertainties which a real integration project may face and by setting restrictions allows one to take into account all information available to the project analyst.

Let us consider the algorithm proposed for estimating the synergistic effect in mergers and acquisitions with the use of simulation technologies:

1) the choice of activity options of integrated companies directly affecting the synergistic effect and included in the calculation model;

2) the construction of cash flow model of the merged company;

3) setting the type and characteristics of probability distributions for the parameters of the merged company; 4) carrying out statistical tests, obtaining random realizations of parameter values;
5) a statistical analysis of simulation results and interpretation of the results obtained.

In this article, we examined the purchase of one of the coal companies by a Russian steel company, incorporated in 2008 in a government list of strategic companies in Russia, as the example of the merger and acquisition transaction. This should allow the creation of a highly efficient vertically integrated structure possible and result in increased cost of the metallurgical company.

Forecasting and carrying out calculations resulted in a value that evaluates the synergistic effect based on generated incomes of the two business segments of the mergered company ( $S E=348,80$ million U.S. dollars). Since the forecast was created in the form of an algorithm, it is possible to re-count the results of the forecast for the different set of input data values. This makes possible to implement the Monte Carlo method for statistical tests [8-11].

Sensitivity analysis found that the most critical parameters in evaluation of the synergistic effect are - cost value of a ton of metal production (each 1\% decrease under otherwise equal conditions results in increased SE by $16.75 \%$ );

- cost value of a ton of coke concentrate (each $1 \%$ decrease under otherwise equal conditions results in increased SE by $8.22 \%$ );

- coke concentrate production (each 1\% decrease under otherwise equal conditions results in increased SE by $3.68 \%)$.

In practice, normal and uniform distribution laws are more common in the generation of the input parameters of the projects. In this study, we used the normal distribution law to generate the input parameters. Table 1 presents the values of parameters required for generation of random numbers for the most sensitive factors for synergy valuation.

Table 1. The values of parameters required for generation of random numbers according to the normal distribution law.

\begin{tabular}{|c|c|c|c|}
\hline No & Indicator & Expected value $\boldsymbol{\mu}$ & $\begin{array}{c}\text { Standard } \\
\text { deviation } \\
\boldsymbol{\sigma}\end{array}$ \\
\hline 1 & $\begin{array}{c}\text { Cost value of } \\
\text { metal production, } \\
\text { million USD }\end{array}$ & 16915.37 & 6121.02 \\
\hline 2 & $\begin{array}{c}\text { Cost value of 1ton } \\
\text { of coke } \\
\text { concentrate, USD }\end{array}$ & 117.87 & 16.82 \\
\hline 3 & $\begin{array}{c}\text { Coke concentrate } \\
\text { production, kt }\end{array}$ & 4284.07 & 544.25 \\
\hline
\end{tabular}

The most effective methods for determining the number of tests are methods for reducing dispersion [1214], such as:

- use of Chebyshev's Theorem;

- use of Spalding formulas;

- estimation of set standard deviation as a measure of dispersion of sample values.

Chebyshev's inequality says that at a given number $\mathrm{k}$ and a random sample $\mathrm{x}_{1}, \mathrm{x}_{2}, \ldots, \mathrm{x}_{\mathrm{n}}$ of size $\mathrm{n}$ at least 1$1 / \mathrm{k}^{2}$ measurements are close to the average value of $\mu$ at a distance of no more than $\mathrm{k}$ of standard deviations. This 
inequality is valid for any distributions of sets, and you can use Chebyshev's inequality to determine sample size, which has the form

$$
\mu_{D}(w, i)=\min _{\omega \in W}\left(1,1-\mu_{A}(v)+\mu_{B}(i)\right)
$$

If we want to estimate the parameter of a simulation model into the interval $A \in D, B \in D, v \in A, i \in B$. with a probability of 0.95 , then $\mathrm{n}$ is 320 . If we want to estimate the parameter of a simulation model into the interval with a probability of 0.05 , then $n$ is 720 .

Table 2 shows the sample size obtained by using Spalding formulas.

Table 2. The sample size corresponding to the desired precision in calculations and significance value.

\begin{tabular}{|c|c|c|c|}
\hline \multirow{2}{*}{$\begin{array}{c}\text { Desired } \\
\text { precision }\end{array}$} & \multicolumn{3}{|c|}{ Significance value } \\
\cline { 2 - 4 } & $\mathbf{0 . 1 0}$ & $\mathbf{0 . 0 5}$ & $\mathbf{0 . 0 1}$ \\
\hline $\mathbf{0 . 1 0}$ & 149 & 185 & 266 \\
\hline $\mathbf{0 . 0 5}$ & 596 & 740 & 1063 \\
\hline $\mathbf{0 . 0 4}$ & 913 & 1156 & 1655 \\
\hline $\mathbf{0 . 0 3}$ & 1650 & 2053 & 2950 \\
\hline $\mathbf{0 . 0 2}$ & 3721 & 6084 & 6643 \\
\hline $\mathbf{0 . 0 1}$ & 14884 & 18496 & 26569 \\
\hline $\mathbf{0 . 0 0 1}$ & 1488400 & 1849600 & 2656900 \\
\hline
\end{tabular}

Among dispersion reduction techniques for finding the sample size $n$ evaluating set fluctuation is the most effective. The problem of estimating dispersion of a set can be put as a task to find such $\mathrm{s}^{2}$ evaluation that

$$
P\left\{(1-d) \sigma^{2} \leq s^{2} \leq(1+d) \sigma^{2}\right\}=1-\alpha,
$$

where $0 \leq d \leq 1$ is a number characterizing the similarity degree of estimation s2 to true dispersion $\sigma 2$ [15-16].

Maze and Cox demonstrated that it is more convenient to use in this equation $\chi 2$ - the statistic (n1)s $2 / \sigma 2$ with (n-1) degrees of freedom, which allows you to find the confidence probability independent of $\sigma 2$ [17-18]. If $\mathrm{n}$ is large enough then $\chi^{2}$ distribution can be approximated by a normal distribution, then

$$
i_{j} \in C_{\alpha}
$$

where $F(C)=\frac{1}{\alpha_{\max }} \int_{0}^{\alpha_{\max }} M\left(C_{\alpha}\right) d \alpha$ is the standard normal statistic for the original probability.

If we want $s^{2}$ to be different from $\sigma^{2}$ no more than in $5 \%$ with the probability of 0.95 then $\mathrm{n} \approx 3075$; if we want $\mathrm{s}^{2}$ to be different from $\sigma^{2}$ no more than in $10 \%$ with a probability of 0.95 then $n \approx 770$.

The next stage of the simulation was the stage of statistical tests implemented by using the Monte Carlo method [19-20]. The values of the input parameters were generated according to the normal distribution, the sample size was 3075. Simulation experiment was carried out in the AP Excel environment with the help of a random number generator.

3075 experiments at a significance level of $95 \%$ were generated and a sample of estimates for the synergistic effect was obtained based on the normal distribution; all these resulted in the calculated statistical characteristics of distribution:

- $\mu(\mathrm{SE})=313,67$ million USD;

- $\sigma(\mathrm{SE})=117,59$ million USD;

- $v(\mathrm{SE})=37,49 \%$ (coefficient of variation);

- $\min (\mathrm{SE})=75,15$ million USD;

- $\max (\mathrm{SE})=519,13$ million USD;

- Median (SE)=337,87 million USD.

Simulation allows you to determine not only the average and the most probable estimation of the synergistic effect, but also to estimate the probability of obtaining a certain annual cash flow in different segments of the merged company that is necessary for the compilation of production and financial programs of a vertically integrated holding company.

Within the possible deviations of the synergistic effect from the forecasted, it is possible to argue that the synergistic effect will fall below the value of $361,460,000$ million USD with the probability of $44 \%$. Since the range space of the synergistic effect resulted from statistical simulation the dispersion of values characterizes the uncertainty of the estimated SE, measured by the standard deviation $\sigma(\mathrm{SE})$ is $117,590,000$ million USD. Then the coefficient of variation is equal to $37.49 \%$.

At the same time the probability that the value $\mu_{S_{5}}(x)=1-x, x \in I \quad$ is greater than $\mu(\mathrm{SE})+\sigma=431,260,000$ million USD is equal to $11.84 \%$. The hit probability of the value of the coal company in the range of $(\mu(\mathrm{SE})-\sigma, \mu(\mathrm{SE}))$ is equal to $34.13 \%$.

Table 3 presents the scale of the level for compliance risk assessment of evaluation of the synergistic effect in the merger and acquisition transaction to the coefficient of variation developed by the authors, according to which an investor considers both the final price for the target company and the possibility of implementing an integration project under the existing conditions.

Table 3. The compliance scale of the level for risk assessment of the synergistic effect to the coefficient of variation.

\begin{tabular}{|c|c|}
\hline Risk level & $\begin{array}{c}\text { The coefficient of } \\
\text { variation }\end{array}$ \\
\hline Light risk & $<0.1$ \\
\hline Moderate risk & $0.1-0.2$ \\
\hline Strong risk & $0.2-0.5$ \\
\hline Critical risk & $>0.5$ \\
\hline
\end{tabular}

In this integration project the level of risk assessment of the synergistic effect is estimated as strong (37.49\%). But since the metallurgical company gives the priority to this M\&A- project, the implementation of the integration project in order to create a vertically integrated holding company in the industry of Russia is expedient at a cost of no more than $V_{\text {инт. }} \approx 463,99$ million USD.

\section{Conclusion}

Thus, the statistical approach proposed to the analysis of the efficiency of merger and acquisition transactions in the industry of the Russian Federation makes it possible 
to predict the synergistic effect in the integration transactions. The values obtained allow systematically exploring the factors of the change in the performance of the integrated company in the real sector of the economy; to estimate risk assessment of the synergistic effect; to give grounds for management decisions relating to a particular integration project which should be accepted or rejected within the framework of improving the competitiveness of the industry of the Russian Federation.

The work is performed under the grant of the President of the Russian Federation for state support of young Russian scientists — PhDs (MK-5339.2016.6)

\section{References}

1. E. Campbell, K. Summers, Lachs strategic synergies (Peter, St. Petersburg, 2004)

2. M. Polikarpova, Risk analysis and the effectiveness of mergers and acquisitions of Russian companies (NPO MAX Group, Moscow, 2012)

3. V. Mkhitarian, M. Polikarpova, Problems of the theory and practice of management, 2, 114-123 (2013)

4. P. Lapshin, A. Khachaturov, Management in Russia and Abroad, 2, 21-30 (2005)

5. E. Khrustalev, O. Khrustalev, The economic analysis: theory and practice, 45, 11-16 (2011).

6. T. Rubinshtein, Russian Journal of Non-Ferrous Metals, 6, 516-518 (2011)

7. R. Shannon, Systems simulation. The art and science (Mir, Moscow, 1978)
8. R. Barlow, F. Proschan, Mathematical theory of reliability (SIAM, 1996)

9. K. Brownlee, Statistical theory and methodology in science and engineering (Wiley, 1965)

10. N. Kremer, Probability theory and mathematical statistics (Unity, Moscow, 2003)

11. N. Kremer, Mathematical statistics (Economic Education, Moscow, 1992)

12. I. Eliseeva, Statistics (Yurayt Publishing, Moscow, 2012)

13. V. Mkhitarian, Data analysis (Yurayt Publishing, Moscow, 2016)

14. Y. Sazhin, N. Rodionov, Statistical methods for research on the socio-economic processes (Publisher Mordovia University, Saransk, 1998)

15. S. Aivazian, V. Mkhitaryan, Applied Statistics and Econometrics fundamentals. Volume 1: Theory of Probability and Statistics, specialty Applied (UNITY-DANA, Moscow, 2001)

16. S. Aivazian, I. Enyukov, L. Meshalkin, Applied Statistics. Dependency Research (Finance and Statistics, Moscow, 1985)

17. E. Wentzel, L. Ovcharov, The theory of stochastic processes and its engineering applications (Nauka, Moscow, 1991)

18. E. Wentzel, L. Ovcharov, Theory of Probability and its engineering applications (Nauka, Moscow, 1988)

19. E. Chetyrkin, I. Kalikhman, Probability and Stick styles (Finance and Statistics, Moscow, 1982)

20. V. Gmurman, Theory of Probability and Mathematical Statistics (Higher School, Moscow, 1977) 